\title{
DIMENSÕES DO CUIDADO: TERRA E AGROECOLOGIA PARA AGRICULTORAS DO MST
}

\author{
DIMENSIONS OF CARE: EARTH AND AGROECOLOGY FOR MST WOMEN FARMERS
}

\begin{abstract}
RESUMO
O texto discute como as experiências de agricultoras agroecológicas Sem Terra, e as diferentes esferas da relação que elas estabelecem com a terra, permitem revisitar e expandir o conceito de cuidado. Foram utilizadas entrevistas com quatro agricultoras assentadas, em associação com uma revisão conceitual sobre o histórico e as particularidades do acesso das mulheres à terra, e a teoria do cuidado enquanto conceito político feminista. A terra, nesse contexto, é interpretada em múltiplos significados: é um objeto de manejo, é um elemento dos fluxos biogeoquímicos, é território e é também uma fonte de identificação para as mulheres enquanto corpo que abriga a vida. As experiências cotidianas dessas mulheres evidenciam a abrangência das relações de cuidado, bem como a potência e necessidade política de construção desse conceito que abarca dimensões humanas e não humanas ao visibilizar a ecodependência das nossas vivências.
\end{abstract}

Palavras-chave: Cuidado. Agricultoras. Terra. Agroecologia.

\begin{abstract}
The text discusses how the experiences of agroecological landless farmers, and the different spheres of the relationship they establish with the earth, allow us to revisit and expand the concept of care. Interviews with four settled farmers were used, in association with a conceptual review of the history and particularities of women's access to land, as well as the theory of care as a feminist political concept. In this context, earth is interpreted in multiple meanings: it is an object of management, it is an element of biogeochemical flows, it is territory and it is also a source of identification for women as a body that shelters life. The daily experiences of these women show the breadth of care relationships, as well as the power and political need to build this concept to encompass human and non-human dimensions when making the eco-dependency of our experiences visible.
\end{abstract}

Keywords: Care. Women Farmers. Earth. Agroecology.

Isabela Noronha

Doutoranda em Ambiente e Sociedade, Núcleo de Estudos e Pesquisas Ambientais (Nepam), Universidade Estadual de Campinas. E-mail: noronha13@gmail.com

Lais S. Fraga

Doutora em Política Científica e Tecnológica pela Universidade Estadual de Campinas; Professora Doutora da Faculdade de Ciências Aplicadas (FCA), Universidade Estadual de Campinas, Brasil. E-mail: lais.fraga@fca.unicamp.br 


\section{Introdução}

Este artigo tem como perspectiva a identificação e visibilização das atividades de cuidado, sob diferentes aspectos, relacionadas ao cotidiano de agricultoras Sem Terra $^{1}$ que têm na agroecologia sua principal forma de produção. O objetivo dessa proposta é compreender como as dinâmicas do cuidado, circunscritas em um contexto de divisão sexual do trabalho, se apresentam e se envolvem na particularidade das experiências das mulheres que lutam pelo acesso e permanência na terra.

Articulamos esta discussão a partir de dois conceitos polissêmicos e fundamentais: terra e cuidado. A terra é trazida justamente por seus múltiplos significados: é o objeto de manejo que fornece o sustento, é um elemento dos fluxos da natureza que interliga água e biodiversidade, é o território que permite a existência e a resistência dos povos no campo, e é também uma fonte de identificação para as mulheres enquanto corpo que abriga e sustenta a vida. Todas essas interpretações representam aspectos que lhes têm sido negados pela racionalidade da agricultura produtivista e patriarcal, que vê na terra apenas o solo: superfície de manejo que pode ser manipulada, explorada e exaurida. A agroecologia aparece nesse contexto como uma alternativa ao modo de produção hegemônico e representa uma forma de fazer agricultura de forma mais cuidadosa, que considera as necessidades das inúmeras relações envolvidas no processo.

O uso do conceito de cuidado se dá no sentido de entendê-lo como uma prática social cujas atividades se inserem no âmbito reprodutivo do trabalho. Por esse motivo, a definição do conceito se torna crucial para o feminismo enquanto uma ferramenta para enfatizar a importância dessas práticas para a sobrevivência e sustentabilidade humana, ao mesmo tempo em que desloca a responsabilidade do âmbito feminino para um contexto em que toda a sociedade está implicada - ou seja, é um esforço de visibilização e de desfeminilização do cuidado. Essas práticas são política e eticamente carregadas, e figuram nas principais preocupações feministas sobre trabalhos desvalorizados. O movimento de associação das práticas cotidianas das mulheres Sem Terra com a Teoria do Cuidado tem aqui duas intenções: tanto revisitar a literatura para pensar a presença e influência de outras categorias que não o contato humano-humano nas teorias sobre o cuidado, como também pensar as implicações políticas de visibilizar e fortalecer justamente o aspecto do cuidado dessas atividades.

As práticas associadas ao cuidado descritas neste artigo são baseadas em entrevistas com quatro agricultoras Sem Terra, realizadas entre novembro e dezembro de 2017, em acampamentos ou assentamentos do MST na região de Campinas. Os perfis das entrevistadas, bem como as particularidades dos assentamentos, apresentam

\footnotetext{
1 A expressão 'Sem Terra', presente algumas vezes no texto, se diferencia do termo 'sem terra', em minúsculo; a primeira é referente à vinculação com o Movimento dos Trabalhadores e Trabalhadoras Rurais Sem Terra (MST), cujos membros se denominam Sem Terra mesmo que já tenham adquirido a propriedade; a segunda expressão aparece para denotar a parcela da população que não possui propriedade rural, independente de vinculação com movimentos sociais.
} 
semelhanças e diferenças que formataram as análises apresentadas ao longo do texto: os elementos que transversalizam as falas e que se referem às percepções e a experiência diária de cada uma delas com a produção, com a agroecologia, com a natureza e com a terra.

$\mathrm{O}$ artigo está organizado com o intuito de apresentar, num primeiro momento, uma revisão de conceitos e teorias que auxiliam na compreensão e estudo da situação das mulheres camponesas. Apresentamos dados que exemplificam a relação das mulheres com a terra no sentido de território - acesso e posse. Em seguida, trazemos a discussão sobre a teoria do cuidado, com as principais articulações mobilizadas pelo conceito, para que possamos pensar no que significa o cuidado no contexto proposto. As descrições e análises das entrevistas realizadas são apresentadas na sequência, enfatizando as práticas associadas ao cuidado, e posteriormente, uma articulação teórica que possibilite o entendimento das relações entre cuidado, gênero, agroecologia e a relação com a terra presentes nas entrevistas. Os caminhos percorridos no texto, entre teoria e atividades de campo, constroem um panorama que descreve a relação entre as múltiplas visões sobre o solo/terra e o impacto na vida da população rural, considerando tanto a visão hegemônica da ciência e da agricultura industrial quanto visões alternativas, particularmente da agroecologia.

Partindo de uma perspectiva feminista, portanto, pensar as relações de poder, interpretações e usos que envolvem o solo e a terra implica pensar em como as mulheres se relacionam (e se relacionaram historicamente) com a terra: como interpretam, como vivenciam, como acessam e como cuidam, por exemplo. Ouvir as mulheres Sem Terra talvez seja uma oportunidade para entender o que querem com a terra aquelas a quem os direitos mais básicos são negados.

\section{Terra como território: o que reivindicam as mulheres}

Mulheres agricultoras desempenham diariamente um papel crucial para suas famílias e comunidades: garantem a saúde e o bem-estar das pessoas por meio da oferta de alimentos diversificados e nutritivos. De acordo com a FAO (2013), cerca de $43 \%$ da força de trabalho agrícola nos países considerados 'em desenvolvimento' é de mulheres e, ao mesmo tempo, essas mulheres enfrentam severas dificuldades de acesso a direitos básicos, além de autonomia e reconhecimento. Dentre as inúmeras desigualdades que perpassam a existência das mulheres, o acesso à terra é um dos mais expressivos dados que indicam a situação desigual de homens e mulheres no campo: segundo Claudia Korol (2016), apenas cerca de $2 \%$ da terra no mundo é de propriedade de mulheres. Os dados de propriedade são complementados pelos dados de atividades desenvolvidas: a carga horária desempenhada diariamente por mulheres do meio rural chega a doze horas, envolvendo diferentes práticas de cuidado, como com a horta, criação 
de animais, processamento e preparo de alimentos, atividades comerciais diretas ou indiretas, além do concomitante cuidado com crianças e pessoas enfermas (KOROL, 2016). A essas atividades se somam outros trabalhos, remunerados ou não, com maior frequência em condições precárias do que em relação aos homens (FAO, 2013). Korol (2016) acrescenta que, apesar da extensa carga horária e de diversas atribuições, o trabalho feminino no campo não é considerado produtivo economicamente, além de na maioria dos casos as mulheres não serem as proprietárias da terra em que trabalham.

No Brasil, de acordo com o Relatório Oxfam (2016), apenas 12,7\% dos estabelecimentos rurais são de propriedade de mulheres, o que corresponde a apenas $5,5 \%$ da área rural brasileira. Dentre os produtores rurais sem terra, o número de mulheres é quase o dobro se comparada aos homens: 8,1\% do total de produtoras e produtores rurais correspondem a mulheres sem terra, enquanto os homens sem terra compõem 4,5\% do total (Oxfam, 2016). A proporção entre mulheres e homens produtores rurais não explica essa desigualdade: a composição é $48 \%$ de mulheres e $52 \%$ de homens. Embora a população rural pobre em geral sofra com diversas formas de discriminação e desigualdade de acesso a direitos, são as mulheres quem, nessas condições, saem mais prejudicadas (SHIVA, 2004; KOROL, 2016). Segundo Maria Emilia Pacheco (2009), são as mulheres que compõe a maior parcela de pessoas vivendo abaixo da linha da pobreza, sujeitas à fome e desnutrição. As barreiras que impedem o acesso a recursos produtivos e financeiros, como terra, assistência técnica e crédito, que garantiriam a autonomia de trabalho mulheres rurais, são maiores e fundadas em discriminação por gênero (DEERE, LEÓN, 2001; FAO, 2013).

Deere e León (2001) descrevem como as mulheres têm sido excluídas do acesso à terra e como se dão os processos de luta pela obtenção de direitos na América Latina. Na mesma linha, Korol, no livro 'Somos tierra, semilla y rebeldia' (2016), apresenta o processo histórico de concentração de terras como um dos fundamentos do sistema patriarcal, capitalista e colonial vigente na América Latina. Para elas, o acesso à terra é um dos problemas mais graves enfrentados pelas mulheres rurais no continente, e que deve ser entendido não somente em termos legais e econômicos, mas também políticos, culturais e estruturais, já que traz raízes históricas e está na base de muitos outros problemas invisíveis para a sociedade.

Korol afirma que a conquista e a colonização pelas nações europeias foram os primeiros processos de "estrangeirização da terra e despovoamento dos territórios" hoje latino-americanos (KOROL, 2016, p. 22). A conquista impôs a escravidão e o desvinculação com práticas agrícolas aos povos que antes delas dependiam para sua subsistência e existência. Às mulheres, esse processo impôs ainda violências sexuais e perseguições de seus saberes ancestrais, muitas vezes relacionados à agricultura, rompendo com suas formas de se relacionar com a terra e, consequentemente, com dados fundamentais de sua identidade (KOROL, 2016, p. 23). Assim como Shiva (2004), Korol atribui ao colonialismo patriarcal o estabelecimento de um "saqueio e destruição de territórios e corpos", impondo a "separação dos povos originários da terra, e de seu sistema de vida” (KOROL, 2016, p. 25). A autora acrescenta que a 
separação da terra se deu tanto para os povos indígenas que habitavam o continente anteriormente, como para os povos africanos sequestrados e trazidos como escravos:

Especialmente dura fue la vida de las mujeres negras traídas como esclavas, que durante más de 500 años han resistido las políticas de exclusión, violencia y sometimiento, fortaleciendo sus capacidades de organización y defensa de su identidad, iniciadas en el período colonial [...]. La independência, y aún el fin de la esclavitud, no creo ninguna posibilidad para que accedieran a la tierra o a posibilidades de trabajo en igualdad de oportunidades ni con los varones negros, ni con las mujeres blancas y hombres blancas. (KOROL, 2016, p.28)

A autora afirma que mesmo os processos de independência dos países colonizadores europeus não significaram uma grande mudança nas possibilidades de acesso à terra ou autonomia para as mulheres, o que é explicado parcialmente pelo fato de que os movimentos que reivindicaram as independências dos países sob dominação espanhola foram promovidas principalmente pelas oligarquias "criolas" (filhos de espanhóis nascidos na América). O machismo e o racismo permaneceram como heranças de um colonialismo interno, excluindo mulheres, indígenas e negros, no momento em que se organizava uma sociedade que se pretendia livre e independente (KOROL, 2016, p.37).

Durante o século seguinte, as desigualdades reverberam em um legado de marginalização das mulheres do acesso à terra. Korol (2016) informa que após a independência surgiram diversos movimentos revolucionários populares que reivindicam a distribuição de terras por meio de reformas agrárias. Porém, mesmo nos casos em que houveram conquistas para esses movimentos, as mulheres foram beneficiadas só indiretamente, ao acessar a terra por meio das famílias comandadas pelos homens: não houveram, salvo raros casos, políticas que fomentassem o acesso direto das mulheres às propriedades (DEERE, LEÓN, 2001; KOROL, 2016). Além disso, mesmo dentro dos movimentos, as mulheres foram por muito tempo figuras invisíveis, já que estão presentes frequentemente nas lutas, mas raramente sua participação é relatada (KOROL, 2016; SILIPRANDI, 2015).

De acordo com Siliprandi (2011), só a partir dos anos 1980 no Brasil os movimentos sociais rurais passam a ter manifestações específicas de mulheres: em um primeiro momento, suas lutas foram pelo reconhecimento de sua identidade e direitos como agricultoras (acesso à terra, direitos sociais, previdenciários e sindicais); as reivindicações foram seguidas de aparições públicas em eventos e de importantes conquistas, como a inclusão enquanto beneficiárias da previdência social.

Siliprandi (2011) também aponta que as reivindicações dos movimentos rurais de mulheres se diferenciam dos movimentos mistos por vincularem os temas de saúde e alimentação como elementos importantes na discussão de uma nova perspectiva de desenvolvimento rural, baseado na sustentabilidade e em formas familiares de 
produção. Segundo a autora, dentre as reivindicações surgiram ao mesmo tempo questões relacionadas ao meio ambiente e opressões de gênero, criando assim uma nova realidade: mulheres agricultoras que aliaram dois campos de discussão, o ambientalismo e o feminismo (SILIPRANDI, 2015). As reivindicações iniciais tinham o sentido tanto de afirmar sua posição como sujeitos produtivos da agricultura familiar, como também a aceitação de seu papel de gênero tradicional na produção de alimentos:

[...] são posturas contraditórias, porque, ao mesmo tempo, elas desafiariam esse papel, por exigirem serem reconhecidas como trabalhadoras e cidadãs, mas também reafirmariam a simbiose "mulher-terra-família" como constituinte da identidade feminina no campo. (SILIPRANDI, 2015, p. 118)

Dentro do MST, de acordo com Bruna de Vasconcellos (2015) e Kelli Mafort (2013) as questões de gênero começaram a ser discutidas por lideranças femininas em meados da década de 9o, indicando a necessidade da participação em todas as instâncias de luta, tomada de decisão e organização do movimento. De acordo com Siliprandi (2015), mesmo existindo o entendimento de que as mulheres deviam participar de todas as etapas da luta pela terra, desde ocupações até organizações e enfrentamentos, a abordagem de gênero não era bem vista dentro do movimento pelo receio de que poderia ofuscar a abordagem de classe. Além disso, "apesar de toda experiência vivida nos períodos de 'luta', após a obtenção da terra, era comum que as mulheres voltassem a seus papéis anteriores, subordinadas aos homens" (SILIPRANDI, 2015, p. 120). A insistência no debate por parte das lideranças femininas culmina na criação do Setor de Gênero, em 200o, no Encontro Nacional do MST, com o objetivo de organizar ações que contribuam para a construção de condições mais igualitárias dentro do movimento (MAFORT, 2013). A autora afirma que, embora na prática ainda persistam muitos desafios, a linha política delineada pelo setor "[...] possibilita um novo significado à luta pela terra, onde todos e todas se sentem sujeitos participantes de um processo de mudança.” (MAFORT, 2013, p. 101).

Bruna Vasconcellos (2015) reafirma que os processos de organização da ocupação e estruturação dos assentamentos figuram entre os contextos que contribuem para a superação das barreiras de desigualdade de gênero, já que a situação privilegia a organização do cotidiano e das necessidades de sobrevivência de forma coletiva - as tarefas de educação, saúde e alimentação, normalmente atribuídas às mulheres, são coletivizadas e visibilizadas. Nesses períodos, as mulheres ganham espaço de atuação política e passam a perceber e se engajar com outras formas de opressão e injustiça (VASCONCELLOS, 2015). Ao mesmo tempo, a autora afirma que a conquista da terra e consequente distanciamento dos lotes, bem como das atividades políticas, faz com que se crie um cenário favorável ao aumento da divisão sexual do trabalho, à desarticulação entre as mulheres e da vulnerabilidade a violências domésticas. 
Vasconcellos (2015) e Siliprandi (2015) concordam que, ainda que continue marcada por profundas desigualdades e injustiças, a situação das mulheres rurais tem apresentado sinais de melhora, como consequência da articulação e mobilização nacional de movimentos de mulheres do campo. Principalmente a partir de 2003, foram criadas políticas dedicadas especialmente às mulheres do campo e da floresta, somando-se às conquistas de acesso à documentação, previdência e titularidade da terra, além das possibilidades econômicas e produtivas alternativas por meio de trabalho associado (VASCONCELLOS, 2015).

Algumas dessas lutas e conquistas têm ocorrido por meio da agroecologia, que figura como uma forma de contestação ao modelo de agricultura industrial, mecanizada e de larga escala surgido nos anos posteriores à Segunda Guerra Mundial, imposto e intensamente aplicado sob a égide de grandes corporações (SILIPRANDI, 2015). O conceito não trata apenas de novas formas de manejo, ou um estilo de agricultura alternativa - é, na realidade, uma resposta ao impasse socioambiental gerado pelo padrão de desenvolvimento agrícola, atuando como uma ferramenta de empoderamento e emancipação de comunidades rurais oprimidas.

Siliprandi (2015) acrescenta que a agroecologia tem particular potencial para fortalecer as lutas das mulheres no campo, ao realizar uma interseção entre movimentos feministas, ambientalistas e de luta pela terra. Pode-se considerar, a princípio, que o processo de mudança para tecnologias de produção agroecológicas escancara a invisibilidade do trabalho feminino: as mulheres camponesas sempre exerceram atividades como de cunho extrativistas, criação de animais, processamento de alimentos e outras atividades consideradas secundárias em relação ao cultivo comercial. Estas atividades constituíram os pilares da segurança alimentar, mas também serviram para complementar a renda familiar e criar estratégias de conservação da biodiversidade. Assim, pode-se supor que os projetos agroecológicos outorgam relevância aos espaços de produção em que as mulheres assumem o papel principal, e, portanto, a partir daí as mulheres das comunidades passam a ser reconhecidas como sujeitos autônomos (SILIPRANDI, 2015).

Apesar de todo esse contexto, muitas lutas ainda estão sendo travadas para garantir o real acesso a direitos, como o desafio da falta de autonomia econômica das mulheres rurais, já que seu trabalho voltado ao autoconsumo das famílias não é valorado economicamente. O tópico seguinte se debruça sobre as definições, conflitos e implicações do uso do conceito de cuidado para denotar diversas atividades cotidianas que são, direta ou indiretamente, atribuídas às mulheres.

\section{Teoria do cuidado}

O cuidado é central para a vida diária: querendo ou não, todos os humanos (e não somente) precisam de comida e abrigo, corpos e objetos precisam ser higienizados, enfermidades precisam ser tratadas; da mesma forma, alguém precisa 
cultivar os alimentos, alguém precisa cozinhá-los e alguém precisa dedicar tempo e afeto à criação das crianças. Para Maria Puig de la Bellacasa (2017), o cuidado é onipresente, mesmo que seja por meio dos efeitos de sua ausência, e pode ter diferentes significados para diferentes pessoas. Se relaciona diretamente com necessidades materiais e fisiológicas da existência humana, mas também abrange a esfera afetiva das relações, bem como dimensões não humanas.

Os estudos sobre o cuidado, de acordo com Mariana Marcondes (2013), têm despertado crescente interesse teórico e político enquanto uma categoria que pode acrescentar no debate feminista e nas ações políticas. Os principais esforços de conceituação são produzidos a partir da sociologia do trabalho e na discussão sobre ética, porém uma miríade de abordagens pode ser encontrada.

Puig de la Bellacasa (2017) enfatiza que, ao mesmo tempo em que figura como um conceito estratégico e com potencial político, a noção de cuidado não pode ser tratada com inocência já que não é só ontologicamente, mas também politicamente ambivalente. Joan Tronto (1987), por exemplo, afirma que a associação do cuidado com o feminino é perigosa pois a simples definição de uma dualidade de gênero, em um contexto social que identifica o "masculino" como o padrão, implicará em uma inferiorização da outra esfera. Porém, deve ser considerado que, de fato, a atividade de cuidar é, em grande medida, regida pelo gênero, tanto porque se insere no âmbito das tarefas atribuídas socialmente às mulheres (trabalho da esfera reprodutiva, como definido pela divisão sexual do trabalho), quanto porque as profissões relacionadas a essas atribuições são majoritariamente ocupadas por mulheres.

Os trabalhos que envolvem o cuidado, que deveriam envolver toda a sociedade, o Estado, as instituições privadas e as próprias famílias, são tradicionalmente atribuídos às mulheres, tanto na divisão sexual do trabalho no universo familiar quanto nas instituições de cuidado. (MARCONDES, 2012, p. 92)

Para o feminismo, portanto, pensar nesse conceito ainda exige confrontar as forças de essencialização das práticas femininas, ou a insistente ideia de que o cuidado se refere a atividades inteiramente purificadas, prazerosas e com um valor ético (PUIG DE LA BELLACASA, 2017).

O conjunto de atividades do trabalho reprodutivo, considerado do âmbito feminino, não circunscreve seus atores somente pelo sexo; homens, em menor número, também se ocupam dessas atividades, porém sem alterar generificação e a desvalorização atribuída. Tronto (1987) ressalta a necessidade de que a discussão sobre o cuidado seja desfeminilizada, ou seja, as atividades de cuidado precisam ser entendidas como beneficiadoras e responsabilidade de homens e mulheres, indistintamente. Além disso, essa autora observa as práticas de cuidado em outros grupos minoritários, como entre imigrantes ou pela população negra, para argumentar que o recorte de gênero não é o único possível para o debate sobre cuidados. 
Pensado como um trabalho, as atividades de cuidado podem estar presentes tanto na esfera privada, dentro das famílias, como na esfera pública, mediado por relações de mercado e serviços públicos (MARCONDES, 2013). O domínio privado do cuidado com a família é o arranjo tradicional, invisibilizado e marcado pela subordinação de gênero, e a progressiva inserção das mulheres no mercado de trabalho vem acompanhada da exteriorização dessas atividades do âmbito doméstico para a esfera pública, especialmente a educação e a saúde (MARCONDES, 2013). Em todas essas esferas, sua condição é quase sempre periférica, desprestigiada e negligenciada. Quando é tratado como profissão, apesar de o cuidado passar a ser referido como um conhecimento técnico, é marcado por aspectos subjetivos que tornam as e os profissionais responsáveis por um fluxo de emoções e afetos atravessados por relações de poder entre a pessoa que é cuidada e o cuidador (MARCONDES, 2013). Dessas considerações decorre a formulação da autora sobre o conceito:

[...] entendemos o cuidado como uma prática social que, ancorada na divisão sexual do trabalho, tem como objetivo atender às necessidades humanas concretas, mas também emocionais e psicológicas, pressupondo a interação face a face entre quem cuida e quem é cuidado, em uma relação de interdependência. Trata-se de uma prática social essencial para a sustentabilidade da vida humana. (MARCONDES, 2013, p. 34)

Além do âmbito do trabalho, o conceito de cuidado tem sido também discutido enquanto uma ética, em que o debate se concentra nos modelos de formação de moralidades, as permeâncias do gênero e de hierarquias nesse processo, e a elaboração e tratamento de problemas cruciais para a sociedade: o cuidado e a preocupação com os outros (ARANGO, MOLINIER, 2011; MARCONDES, 2011; KUHNEN, 2014; GILLIGAN, 1982). Nesta perspectiva, uma ética não pautada no cuidado se baseia na "compreensão ideológica do indivíduo autônomo, em que o padrão de sucesso social é o de homem autossuficiente” (MARCONDES, 2013, p. 39), único responsável por seus méritos, que aliada à falsa ideia da independência do sistema econômico se coloca na base lógica da esfera produtiva da sociedade. A crítica a essa lógica da autonomia evidencia, segundo a autora, que os que mais se beneficiam da provisão social e individual para o atendimento de suas necessidades não são os ditos 'dependentes', como seria coerente supor, mas sim aqueles que detém mais poder. É o que Marcondes (2013, citando um conceito de Tronto) chama de irresponsabilidade privilegiada: "são, sobretudo, os homens que mais contam com apoio para atendimento de suas necessidades concretas e emocionais, por meio do cuidado familiar realizado pelas mulheres." (p. 39).

Desse padrão social para a provisão do cuidado decorrem alguns paradoxos: o cuidado, prática essencial para a sustentabilidade 
da vida humana, é desvalorizado; quem cuida, realizando uma atividade central para a sobrevivência humana, é estigmatizado por cuidar; e a população masculina, a quem os esforços sociais de atendimento das necessidades concretas são prioritariamente voltados, é completamente dependente, ainda que a ele se a ela se associe o atributo da independência (MARCONDES, 2013, p. 39)

Enfatizando a justificativa da interdependência humana, Kuhnen (2014) defende que o cuidado seja proposto enquanto uma ética feminista: uma abordagem que amplia os conceitos de moralidade ao se basear na centralidade das práticas e relações de cuidado para nossas vidas e para a sociedade - no mesmo sentido das propostas de tornar a sustentabilidade da vida o eixo das análises econômicas, como em Amaia Orozco (2016) e Corina Enríquez (2012).

Pensando no caso das mulheres agricultoras, porém, as definições anteriores carecem de um olhar mais abrangente com relação a uma série de atividades desenvolvidas cotidianamente nas quais o receptor do cuidado não é diretamente outro ser humano. O cuidado, em suas diversas formas, abarca tanto as dimensões do trabalho doméstico e afetivo de preparo de alimentos, manutenção da casa, atenção às crianças e enfermos, como as demais atividades, preocupações e formas de conhecimento que dão suporte às atividades mais básicas, como a produção de alimentos saudáveis, a criação de animais, a preocupação com a preservação da água e da biodiversidade, o conforto, entre outros. Essas dimensões partem do reconhecimento da nossa inter e ecodependência, ou seja, o reconhecimento da materialidade da existência e das limitações físicas do nosso mundo, como mencionado por Yayo Herrero (2016). O regime socioeconômico capitalista, segundo a autora, se baseia justamente na negação dessas limitações e vulnerabilidades, e cresce as custas daquilo que nos sustém enquanto seres vivos; é, ao contrário, uma consciência dessas limitações que deriva na necessidade de valorização das práticas de cuidado e na expansão da noção de cuidado para além das relações diretas entre humanos:

Uma atividade da própria espécie que inclui tudo o que podemos fazer para manter, continuar e reparar nosso "mundo" para que possamos viver nele da melhor maneira possível. Esse mundo inclui nossos corpos, nós mesmos e nosso meio ambiente, e tudo em que procuramos intervir de forma complexa eautossustentável. (TRONTO, 2007, apud MARCONDES, 2013, p. 33)

O que Puig de la Bellacasa (2015) chama de políticas de cuidado, por exemplo, são um conjunto de atividades que criam mundos onde é possível viver — práticas e experiências vitais que são desconsideradas pelo ethos produtivista, no qual a lógica da produção se sobrepõe às outras atividades de valor, como é o caso da agricultura convencional. 
Pensado dessa forma, o cuidado tem uma relação direta com as diferentes noções de temporalidades - uma multiplicidade de tempos sociais que deriva dos tempos 'naturais', do ciclo da vida (MARCONDES, 2013). É um tempo inelástico, que deve respeitar as necessidades de quem ou do que é cuidado, e por isso mesmo é incompatível com o tempo mercantil:

O tempo do cuidado é também irredutível a um tempo produtivista. [...] Abordagens feministas para o cuidado mostram como o trabalho de reprodução e manutenção da vida tem sido tradicionalmente considerado marginal com relação ao trabalho que gera valor [financeiro]. (PUIG DE LA BELLACASA, 2015, p. 707-708, tradução nossa).

Seja no nível do trabalho interpessoal, corporificado, seja no trato com a terra ou outras relações com a natureza, o cuidado passa por ajustes de acordo com ciclos, contextos e escalas de tempo ecológicas, e exige níveis de dedicação e doação: "O tempo do cuidado pode ser prazeroso e recompensador, mas também cansativo, envolvendo muito desprendimento e ajustes às exigências temporais daquele que é cuidado. " (PUIG DE LA BELLACASA, 2015, p.707, tradução nossa).

$\mathrm{O}$ cuidado com a terra pode ser pensado como uma forma de respeitar uma temporalidade não humana, que não pode ser avaliado por padrões de 'eficiência', o que transforma as práticas de cuidado em formas de resistência. Isaías Acuña (ACUÑA et al., 2015; ACUÑA, MONCAYO, 2015) considera um imperativo ético de cuidar da terra como uma responsabilidade muito além dos agricultores, uma vez que, se superarmos a visão utilitarista para o entendimento do solo como um sistema crucial para manutenção de todos os ciclos ecológicos, "nenhum ser vivo sobre o planeta escapa às dinâmicas, sejam de origem antrópica ou naturais, que atuam sobre ele [o solo]" (ACUÑA et al., 2015, p. 122).

Outro ponto que deve ser observado nessa conceituação é a transversalidade do tema em diversas áreas do conhecimento, o que demonstra sua 'onipresença', como apontou Bellacasa, como também um caminho para a dissociação do tema enquanto uma 'pauta de mulheres'. A presença do conceito em outras disciplinas, embora delineado por outras especificidades, parece extrapolar a ideia para o entendimento de que a existência de todos demanda um cuidado - seja direto ou tecnicamente mediado, material ou afetivo, e dedicado a humanos ou à natureza. De acordo com Deane Curtin (1991), é um reconhecimento da nossa ecodependência.

Em alguns contextos, como relatado por Shiva (2004) e Curtin (1991), a destruição de recursos naturais é uma fonte direta de opressão contra as mulheres:

Cuidar para mulheres em determinado contexto inclui cuidar do seu ambiente. [...] O modelo de cuidado não requer que aqueles que recebem nosso cuidado devam ser "iguais" a nós. E nem supõe que não sejam iguais. É baseado no desenvolvimento 
da capacidade de cuidar, não o critério de igualdade. O cuidado resultante deve levar a um novo senso de empoderamento baseado no cultivo da disposição para agir para empoderar nós mesmos e os outros. (CURTIN, 1991, p. 67-68, tradução nossa)

Puig de la Bellacasa (2017) traduz essas práticas como uma vivência terrana: são todas as atividades cotidianas, mas carregadas de preocupações éticas, políticas e de afeto que fazem com que seja possível nossa existência material - corporificada, situada - e que, por serem tão visceralmente essenciais, são tomadas como dadas. São essas práticas, que envolvem atividades cotidianas relacionadas à alimentação, saúde, conforto, afetos e manutenção de processos, que aparecem com maior frequência nas falas das agricultoras. No tópico seguinte, essas falas são detalhadas e comentadas em articulação com as teorias apresentadas.

\section{As práticas do cuidado no cotidiano Sem Terra}

As quatro agricultoras entrevistadas, apesar de terem percorrido diferentes caminhos, compartilham de um histórico de reivindicação e luta por acesso a uma terra, um território, em que pudessem viver e cultivar. Teresa, Ana, Maria e Margarida² dos assentamentos D. Pedro Casaldáliga, Milton Santos e do acampamento Elizabeth Teixeira, vivem em seus lotes e produzem, por meio da agroecologia, frutas, uma grande variedade de legumes e hortaliças, plantas medicinais, PANCs (Plantas Alimentícias Não Convencionais), alguns cultivos sazonais como milho, feijão e mandioca, além de cuidarem de algumas criações de animais como galinhas, porcos, patos e carneiros. Todas as entrevistadas têm filhos, e, com exceção de Maria, seus filhos participam das atividades agrícolas da família em conjunto. Maria é divorciada e é a única que vive e produz sozinha em seu lote. Margarida e Ana descrevem sem grande distinção o trabalho dos maridos e o seu próprio com relação à agricultura, como se as atividades fossem conjuntas ou complementares, mas Teresa diz que em seu lote quem trabalha na é terra principalmente o marido, enquanto ela própria tem poucas contribuições, se dedicando mais às atividades domésticas.

Assim, os elementos mais relevantes nas conversas foram referentes ao processo de luta pela terra e o encontro com a agroecologia, ao trabalho com alimentação e divisão sexual do trabalho, e ao cuidado nas práticas cotidianas. A relação com a terra emerge a partir de cada um desses pontos: as motivações pela conquista da terra, o tipo de produção, de técnicas e de relações que desejam, o significado atribuído ao cultivo de alimentos saudáveis, as atribuições de gênero na divisão das tarefas, suas práticas diárias de manejo, o conhecimento adquirido e compartilhado entre mulheres, a preocupação com a saúde da família, do consumidor

2 Para manter as interlocutoras anônimas, optei por substituir seus nomes verdadeiros e não entrar em detalhes sobre características dos lotes e assentamentos de cada uma. 
e do ambiente... todos esses elementos estão interligados nas falas e formam uma percepção abrangente do significado da terra para essas mulheres.

A trajetória de luta é talvez o ponto mais divergente entre as entrevistadas. Enquanto Ana esteve envolvida com o Movimento desde sua criação, na década de 80 , as demais conheceram o movimento no momento em que souberam da oportunidade de participar das ocupações nas áreas em que vivem hoje. Em comum, todas compartilham da história de êxodo rural dos pais, que se viram forçados a abandonar a terra e a agricultura e acompanhar a família em busca de novas oportunidades na cidade.

Todas também participaram das ocupações de seus assentamentos, porém trazendo motivações e bagagem diferentes. As motivações para participar das lutas para ter acesso a uma terra se relacionam com o ideal de ter mais autonomia para produzir ou se engajar em algo que lhes garantisse melhores condições de trabalho. Todas passaram por momentos de violentos despejos das ocupações e de fortes resistências para permanência no local, com a vivência da organização das famílias nos acampamentos.

Depois das divisões dos lotes, as entrevistadas lembram da dificuldade de começar a trabalhar em uma terra que estava abandonada e que foi explorada por muito tempo por técnicas agrícolas convencionais. Mesmo para as menos próximas da agricultura, a percepção sobre os efeitos das práticas convencionais para a terra foi marcante: ao chegarem nos lotes, todas relatam a lembrança de um solo degradado pelo uso intensivo anterior - canaviais e/ou pastagem - e coberto por uma espécie invasora de capim que suprime o crescimento de outras plantas.

No momento de estabilização dos assentamentos, ou mesmo do acampamento, o início das discussões das propostas da agroecologia começou a trazer um reconhecimento de esferas ocultas da produção familiar, pela valorização dos conhecimentos e das atribuições trazidos pelas mulheres. A oportunidade de trabalhar com agroecologia surgida pelo acesso à terra e pela formação por meio do movimento é relatada como um momento de realização por estarem trabalhando a partir de práticas que, de uma forma ou de outra, já estão presentes do seu cotidiano, e são dotadas de um sentido objetivo e afetivo:

[Com a agroecologia] Mudou o jeito que mexe com a terra, o modo de preparar, o carinho mesmo que a gente tem com as mudas, com as plantas... até isso deixa a gente calma. (Margarida)

A relação de trabalho, nesse caso, muda de um caráter produtivista adotado pelas práticas convencionais (e presentes não somente na agricultura) para uma relação também afetiva. Para Ana, que acompanhou diversas lutas na região e se lembra do momento em que a agroecologia passou a ser difundida dentro dos assentamentos, o movimento agroecológico começou a tomar forma a partir de mutirões organizados pelas mulheres. Dentro do seu assentamento, esses mutirões 
eram organizados em rodízio, beneficiando cada dia o lote de uma das participantes e, durante esse processo, formatavam um espaço de compartilhamento entre essas mulheres. Era nesse momento em que trocavam mudas e sementes, conhecimentos sobre técnicas, compartilhavam receitas, dúvidas, sofrimentos e experiências, e desses encontros passaram a planejar parcerias e a criação de novos projetos, como a fundação da cooperativa de cestas orgânicas.

No relato de Ana é exemplificada a abrangência da dimensão das discussões agroecológicas: da valorização do trabalho das mulheres surgiram organizações, que levam à emancipação e autoconfiança. É nesse sentido que se direciona a articulação teórica entre feminismo e agroecologia, como trazido pelas autoras:

[...] indicando como a relação entre gênero, meio ambiente e agricultura é solo fértil para pensar-agir em prol dos feminismos como expressão de uma emancipação produtiva libertária, em prol de um futuro na direção de uma ética comum implicada com uma noção de bem viver compartilhado, em que a qualidade de vida humana considere a interdependência e a ecodependência. (LIMA, JESUS, 2017, p. 76)

A mudança do foco da preocupação com o aumento de produtividade para a melhoria da qualidade e diversidade da produção é uma mudança de valores que abarca as relações cotidianas dessas mulheres, e não se restringe às práticas de manejo.

A realização de um trabalho que é diretamente relacionado com a alimentação é central nas experiências das agricultoras, e a atenção de produzir um alimento saudável para a família é estendida para os consumidores. Isso é claro na fala de Ana, que relata que antes da organização da cooperativa (que entrega cestas orgânicas para grupos de consumo), os agricultores (particularmente homens) não lidavam com a produção a partir do entendimento de que aquilo era um alimento, mas sim um produto, um objeto para obtenção do lucro. Foi o trabalho com as cestas, que demanda um cuidado com a seleção e a diversidade do que será enviado, além de promover uma maior proximidade com o consumidor, que mudou a percepção. Nesse caso, as mulheres já estavam acostumadas:

Quando entende aquilo como um alimento a coisa muda, e as mulheres já sabiam disso, porque a mulher sempre tá preocupada com o alimento que a família vai consumir. Tem que ser uma coisa saudável, sem veneno, tem que ser uma coisa gostosa e tem que ser bonita também. (Ana)

A diferenciação entre a produção de alimentos ou um produto qualquer traz uma dimensão da consciência de todo o ciclo de produção e consumo, e uma preocupação com todos os envolvidos nesse processo. Desde a escolha e o preparo 
do cultivo, o manejo, a atenção à diversidade e a consorciação das culturas, até o cuidado com a colheita e o preparo, os processos se orientam com a preocupação de que seja um resultado satisfatório assim como se espera da alimentação que a própria família vai receber. E isso traz a satisfação para o trabalho, pela consciência de que seus frutos são importantes também para outras famílias. Esse ponto também foi observado por Siliprandi (2015), que atribui o orgulho das agricultoras de oferecer alimentos de qualidade para a família e para a comunidade não só para a superação da fome e da desnutrição, mas também para uma valorização da riqueza da variedade de produtos adquirida no processo de transição agroecológica.

Ana afirma com ênfase que as grandes responsáveis pela produção das hortas agroecológicas são as mulheres, com variedade e qualidade. Para ela, os homens, fora do contexto de preparação das cestas, normalmente se atraem mais para produções mais "brutas", de comercialização em maior escala, como milho e mandioca. Já Teresa atribui a diferença das produções à divisão de trabalhos: se a mulher tem que cuidar dos filhos e da casa, fica muito difícil "trabalhar de verdade" na roça - restam os cultivos menores, próximos da casa e voltados para o consumo da família.

Na entrevista de Teresa ficam evidente alguns elementos de invisibilização do trabalho feminino trabalhados pela literatura sobre agroecologia e feminismo. Em vários momentos, Teresa afirma que não participa da produção, não planta nada, "só cuido da casa". Em outros, diz que plantou a berinjela e os tomates próximos da casa. Ao mostrar a pomada produzida pelas mulheres a partir de vinte e sete ervas medicinais, pergunto: “Onde vocês conseguem esses ingredientes?", e a resposta foi "Eu planto todos ali na frente". Ou seja, está presente em sua própria fala a concepção da divisão sexual das tarefas que não considera a contribuição feminina como um trabalho propriamente dito; o trabalho real, nesse caso, é considerado o trabalho masculino, que depende de força e é voltado para a comercialização. Pra Teresa, diferente das falas das outras entrevistas, o esforço com a dedicação às tarefas domésticas inviabiliza a participação das mulheres na produção.

Pensando na divisão sexual do trabalho no meio rural, Mireia Baylina (2004) argumenta que a natureza do trabalho desenvolvido pelas mulheres rurais é imprescindível para a subsistência das famílias, além de contribuir direta ou indiretamente no retorno econômico, mas que essas informações foram omitidas por muito tempo nas pesquisas devido a definições equivocadas de trabalho. Os conceitos chave de trabalho e família até então omitiam a presença e a contribuição das mulheres nos sistemas agrícolas: o trabalho era definido e medido apenas pelas categorias que se baseavam no modelo masculino de atividades, como a jornada diária fixa, ignorando todas as outras atividades da unidade familiar; e família, porque se considerava uma unidade orgânica ideal, liderada e representada por um homem, obscurecendo assim as demais divisões sociais, as opressões e as desigualdades internas (BAYLINA, 2004). Na divisão sexual do trabalho, a principal característica é a designação dos homens às tarefas da esfera produtiva, ou seja, todas as funções com valor social e financeiro agregado; enquanto as mulheres são designadas à esfera reprodutiva: as atividades do âmbito doméstico (Helena HIRATA, Daniele KERGOAT, 
2007). Essas duas esferas se relacionam de maneira fortemente hierarquizada, considerando a esfera reprodutiva inferior e subordinada à produtiva.

Ana, por exemplo, relata que se dedica menos do que gostaria aos cultivos não por uma atribuição feminina, mas pela carga de trabalho enquanto dirigente. $\mathrm{E}$ Margarida não chega a dissociar o que entende por trabalho doméstico e de cultivo. A divergência na fala de Teresa é importante para ilustrar que a invisibilidade do trabalho feminino ainda existe, e o processo entre a aproximação com as discussões da agroecologia e a mudança das percepções e das práticas não é natural e espontâneo. Essa transição normalmente é acompanhada da organização de mulheres para compartilharem suas experiências e articularem sua mobilização política para reconhecimento em suas casas, nos acampamentos e na destinação das políticas. Dentre as discussões, desponta a questão do trabalho doméstico:

Se considera que as práticas de alimentação familiar são trabalho porque a transformação dos alimentos em comida requer um gasto de tempo e energia no acesso, seleção, preparação e disposição dos alimentos para ser consumidos. [...] Constitui trabalho de cuidado, porque a comida se enquadra em relações e vínculos familiares e sociais que estabelecem obrigações e responsabilidades a respeito de quem deve desempenhar estas tarefas e quem se beneficia delas. (PATIÑO, 2010, p. o6, tradução nossa)

As dimensões do cuidado, muito mais do que faladas, são percebidas e vivenciadas. É no carinho com que falam da produção, no orgulho em mostrar o trabalho, a atenção com todas as etapas e com a continuidade dos processos...esses elementos se relacionam diretamente com as atribuições de tarefas para as mulheres, pois o trabalho com a terra, seja comercial ou não, passa a ser uma extensão dos trabalhos domésticos.

O cuidado com a vida humana e com as necessidades básicas têm uma dimensão objetiva (necessidades biológicas) e outra subjetiva (que inclui afeto, cuidados, segurança psicológica, relações e laços humanos significativos). Os trabalhos domésticos estão voltados, em grande parte, a atender essas duas dimensões das necessidades humanas. (LIMA e JESUS, 2017, p. 87)

O cuidado se relaciona diretamente com a preocupação com a alimentação, mas mistura as dimensões práticas e afetivas:

[...] o cuidado abarca muito mais que um vínculo direto entre duas pessoas, implica a atenção indireta que recebem as pessoas no marco de vínculos familiares e sociais, através da qual se procura gerar bem-estar. Neste caso, a alimentação constitui 
uma expressão de cuidado para os membros da família e para outros parentes, vizinhos e amigos com quem se estabelecem proximidades e vínculos mediante os quais se desenvolve a vida social. (PATIÑO, 2010, p. 07, tradução nossa)

Margarida mostra com pesar as árvores que morreram em tempestades, por queimadas ou por motivos desconhecidos. Maria, ao me mostrar uma árvore que pretendia cortar para priorizar o crescimento do abacateiro vizinho, conta que desistiu ao perceber que dos galhos pendiam duas pequenas graviolas:

Essa fugiu do machado. Não posso cortar uma árvore que tá com fruta né? (Maria)

Margarida e Maria também demonstram muito carinho pelas criações (de porcos, galinhas, patos e ovelhas), de uma maneira tão expressiva que me pareceu até indelicada a pergunta sobre qual era a função comercial dos animais. A comercialização existe, mas pelas falas, é uma etapa necessária, mas muito menos marcante do que a atenção diária com a alimentação, limpeza e cuidados. Outra justificativa para a manutenção das criações é a reutilização do esterco nas próprias plantações.

Para Ana, a agroecologia teve o papel não apenas de visibilizar o conhecimento e as práticas do âmbito reprodutivo, mas também de ampliar as relações de cuidado às tarefas masculinas. Esse cuidado deriva de uma atenção dada às relações de interdependência entre todos os envolvidos no processo: família, cooperativa, consumidores e parceiros. Ao valorizar atribuições femininas da produção, a agroecologia modificou as formas de entendimento e de vivência das experiências:

[A agroecologia] Mudou o tratamento, o cuidado com a colheita, o cuidado com as cestas, o cuidado até com a boniteza, porque o pessoal que recebe também quer comer um negócio bonito; não é porque é orgânico que pode ser um legume amassado, uma coisa de qualquer jeito. (Ana)

A sensibilidade estética, como a preocupação com a "boniteza" das cestas, também é comum quando se trata das relações de cuidado, desde o relato sobre a autoestima das agricultoras até a disposição e organização dos espaços nos lotes das mulheres. Não é raro que os caminhos para acessar e circular dentro dos espaços sejam pontuados por uma grande variedade de flores e folhagens ornamentais. Maria, por exemplo, coleciona orquídeas espalhadas por muitas das árvores e troncos secos espalhados pelo terreno; Margarida aguarda o florescimento dos diversos cactos que cultiva na propriedade.

Outro ponto que aparece, explícita ou implicitamente, nas falas, foi a relação que o tipo de agricultura impõe com o tempo. Trabalhar com a agroecologia ou com as 
agroflorestas muda o tipo de retorno que se espera do cultivo, os ciclos de atividades e, portanto, como as pessoas organizam seu tempo. A agricultura convencional, praticada no passado ou observada na vizinhança, se baseia em uma expectativa de alto rendimento: espera o maior ganho com a menor dedicação possível. É essa premissa que permite a homogeneização das culturas e a adoção de "atalhos", como os fertilizantes e agroquímicos.

Apesar da concepção de um tempo mais 'livre', foi frequente nas entrevistas a pontuação da necessidade de dedicação diária e constante observação de toda a produção. Ou seja, o tempo que precisa ser acompanhado é o tempo natural dos processos de crescimento e desenvolvimento das plantas e dos animais, e a tarefa que as agricultoras desempenham é de intermediar ou orientar esses crescimentos para o objetivo pretendido - observar a falta ou excesso de água, sombreamento, proteger de predadores e competidores, etc. Dessa observação e atenção diárias nasce uma compreensão de como os processos complexos tomam forma no quintal e criam uma forma de conhecimento derivado da vivência prática das atividades de cuidado:

O reconhecimento do papel das mulheres como observadoras, investigadoras e criadoras de novos conhecimentos permitelhes construírem uma visão não tradicional do seu papel como responsáveis pela alimentação da família. Em um nível ideal, como proposta, essa não será mais uma atividade rotineira, feita por obrigação, mas um campo de ação importante, que exige conhecimentos, capacidade e competência, e pelo qual elas serão as responsáveis. Na prática cotidiana, não é exatamente assim que funciona, e elas sabem disso. (SILIPRANDI, 2015, p. 306)

Esses conhecimentos são, em outras palavras, a percepção da nossa inter e ecodependência nas relações observadas cotidianamente. Ampliando toda essa discussão, as percepções e as práticas trazidas pelas agricultoras entrevistadas se relacionam com a preocupação com a politização dessa discussão, perpassando outras esferas produtivas, trazidas na literatura:

As preocupações pela questão da preservação das sementes crioulas ou seu engajamento com a tradição das plantas medicinais e mais recentemente a incorporação por muitos movimentos de mulheres populares no projeto da agroecologia, desde essa perspectiva analítica podem ser entendidos como esforços concretos dessas mulheres de politizar o cuidado com a saúde das famílias e com o meio ambiente, não perdendo, vale destacar, o norte político de se repensar a questão fundiária e de distribuição de terras. (VASCONCELLOS, 2017, p. 364)

Em síntese, as experiências dessas mulheres agricultoras Sem Terra evidenciam a abrangência das relações de cuidado, bem como a potência política 
da construção do conceito. O conceito de cuidado visto a partir dessas experiências abarca dimensões humanas e não humanas ao visibilizar a ecodependência das práticas, e a materialidade presente na construção do conceito perpassa, além das experiências das práticas do âmbito reprodutivo do trabalho, o histórico de lutas por acesso e permanência na terra.

\section{Considerações finais}

$\mathrm{O}$ artigo discute como as experiências de agricultoras Sem Terra, e as diferentes esferas da relação que elas estabelecem com a terra, permitem revisitar e expandir o conceito de cuidado. A ideia de associar as práticas cotidianas dessas agricultoras orientadas pela agroecologia, sua ampla relação com a terra e a teoria do cuidado explicita um duplo movimento: visa tanto a visibilização e valorização das atividades e experiências das agricultoras, como também traz uma contribuição teórica ao expandir a noção de cuidado para além das relações humanas.

A abordagem que atribuímos ao conceito de cuidado é em grande medida guiada pela discussão retomada por Maria Puig de la Bellacasa (2014; 2015; 2017) e que propõe uma exploração especulativa dos significados do cuidado para pensar a interdependência das formas de vida. Para essa autora, é essencial conceber o cuidado como um trabalho concreto de manutenção, com diretas implicações éticas, materiais e afetivas, bem como políticas. Diversas formas de cuidar são identificadas e pesquisadas, empírica e concretamente, e uma ampla gama de abordagens é usada para construir esse conceito, com contribuições específicas e variadas; embora essas abordagens nem sempre estejam de acordo entre si, elas compõem um entendimento da relevância da compreensão dessas práticas.

A agricultura praticada pelas mulheres ouvidas carrega o cuidado como eixo estruturante da produção familiar, da preocupação com a saúde e do bem-estar de todos os envolvidos nos processos - entre humanos e não humanos. Essas práticas de cuidado são marcadas por diferentes relações com a terra, que é a materialização de uma possibilidade de autonomia para essas mulheres: enquanto o território a que se pertence, enquanto o terreno que foi obtido por meio de luta, e enquanto o solo, que permite a agricultura, o sustento e a criação.

A teoria do cuidado, portanto, é politicamente potente ao visibilizar diversas atividades cotidianas, essenciais à sustentabilidade da vida, frequentemente associadas à trabalhos com carga afetiva, e que são atribuídas, em grande medida, às mulheres. Por outro lado, é uma proposta delicada, já que se coloca apartada de uma discussão cara para os feminismos que se coloca entre dois pólos: o da essencialização, em que as mulheres, por serem mulheres, sabem e devem cuidar; e o de uma relação de aversão e negação da função de cuidar, em que a atividade é narrada como a causadora (ou o condicionante) da opressão da mulher na sociedade e, portanto, deve ser evitada. O fundamento da teoria do cuidado trazida no texto não se associa com 
essas perspectivas, até mesmo por compreendermos que a própria categoria mulher está em disputa nessa discussão.

A intenção é enfatizar a noção de que somos seres inter e ecodependentes, e que a sociedade se sustenta por meio de cotidianas atividades de cuidado entre humanos e não humanos. Essas atividades são tanto essenciais quanto invisibilizadas - justamente por serem corriqueiras, são tomadas como dadas e, embora não seja devido a nenhuma característica intrínseca do que constitui as mulheres, é hoje realizada em grande parte por mulheres, com sobreposição de recortes de classe e de raça. E por isso a proposta de desfeminilizar o cuidado não significa um esforço para que as mulheres deixem de realizar essas atividades em absoluto, mas, ao contrário, que seja reconhecido o caráter vital desses processos que precisam estar presentes no dia-a-dia de todos nós; a valorização da nossa interdependência perpassa, também, o reconhecimento de que essas atividades devem ser atribuição de todos e de que o objeto do cuidado não se restringe ao universo humano.

\section{Referências}

ACUÑA, Isaías T.; MONCAYO, Franco H. O. "El imperativo de la agricultura hoy: cuidar la tierra" Luna Azul, v. 41, p. 385-396, 2015.

ACUÑA, Isaías T. et al. "De la conservación del suelo al cuidado de la tierra: una propuesta ético-afectiva del uso del suelo". Ambiente E Sociedade, v. 18, n. 3, 2015.

ARANGO, Luz G.; MOLINIER, Pascale. "El cuidado como ética y como trabajo". In: ARANGO, Luz G.; MOLINIER, Pascale. (Eds.) El trabajo y la ética del cuidado. Medellín: La Carreta, 2011.

BAYLINA, Mireia. "Metodología para el estudio de las mujeres y la sociedad rural". Estudios Geográficos, v. 65, n.254, p. 5-28, 2004.

CURTIN, Deane. “Towards an Ecological Ethic of Care”. Hypatia, v.6, n.1, p. 6o-75, 1991.

DEERE, Carmen D.; LEÓN, Magdalena. Empowering women: land and property rights in Latin America. Pittsburgh: University of Pittsburgh Press, 2001.

ENRÍQUEZ, Corima. "La cuestión del cuidado:¿ El eslabón perdido del análisis económico?". Revista Cepal, 2012.

FAO - Organização das Nações Unidas para Agricultura e Alimentação. Política de igualdad de género de la FAO. Roma, 2013 
HERRERO, Yayo. "Economía Feminista y Economía Ecológica, el diálogo necesario y urgente". Revista Economia Crítica, n. 22, 2016.

HIRATA, Helena; KERGOAT, Danièle. "Novas configurações da divisão sexual do trabalho". Cadernos de Pesquisa, v. 37, n. 132, p. 595-609, set./dez. 2007.

KOROL, Claudia. Somos tierra, semilla, rebeldía: mujeres, tierra y territorio en America Latina. GRAIN, Acción por la Biodiversidad y América Libre, 2016.

KUHNEN, Tania A. "A ética do cuidado como teoria feminista”. In: SIMPÒSIO DE GÊNERO E POLÍTICAS PÚBLICAS, III edição, 2014, Londrina - PR, Universidade Estadual de Londrina. Anais, 2014.

LIMA, Márcia M. T.; JESUS, Vanessa B. "Questões sobre gênero e tecnologia na construção da agroecologia”. Scientiae Studia, v. 15, n.1, p. 73-96, 2017.

MAFORT, Kelli. A hegemonia do agronegócio e o sentido da reforma agrária para as mulheres da Via Campesina. 2013. Dissertação de mestrado em Ciências Sociais. Universidade Estadual Paulista, Araraquara, São Paulo, Brasil.

MARCONDES, Mariana M. "A divisão sexual dos cuidados: do welfare state ao neoliberalismo". Argumentum, v.4, n.1, p. 96-106, 2012.

MARCONDES, Mariana M. A corresponsabilização do estado pelo cuidado: Uma análise sobre a Política de Creches do PAC-2 na perspectiva da divisão sexual do trabalho. 2013. Dissertação de Mestrado em Política Social do Departamento de Serviço Social. Universidade de Brasília (UnB), Brasília, Distrito Federal, Brasil.

MOL, Annemarie; MOSER, Ingunn; POLS, Jeannete (Eds). Care in practice: On tinkering in clinics, homes and farms. Vol. 8. Bielefeld: Transcript Verlag, 2010.

OROZCO, Amaia P. Subversión feminista de la economía - Aportes para un debate sobre el conflicto capital-vida. Madrid: Traficantes de sueños, 2016.

OXFAM. Terrenos da desigualdade: Terra, agriculturas e desigualdades no Brasil rural, 2016.

PACHECO, Maria Emilia L. "Os caminhos das mudanças na construção da agroecologia pelas mulheres”. Agriculturas: experiências em agroecologia, v6. N.4, Rio de Janeiro, 2009. 
PATIÑO, Sandra M. F. "La alimentación familiar: una expresión del cuidado no remunerado". Prácticas de ofícios - investigación y reflexión en Ciencias Sociales, n. 6, 2010.

PUIG DE LA BELLACASA, Maria. "Matters of care in technoscience: Assembling neglected things". Social Studies of Science, v.40, n.1, p.85-106, 2011.

PUIG DE LA BELLACASA, Maria. "Encountering Bioinfrastructure: Ecological struggles and the sciences of soil”. Social Epistemology, v.28, n.1, p.26-40, 2014.

PUIG DE LA BELLACASA, Maria. "Making time for soil: technoscientific futurity and the pace of care”. Social Studies of Science, v.45, n.5, p.691-716, 2015.

PUIG DE LA BELLACASA, Maria. Matters of care: Speculative Ethics in More than human worlds. University of Minnesota Press, 2017.

SHIVA, Vandana. Abrazar la vida: Mujer, ecología y supervivência. Madrid: Horas y horas, 2004.

SILIPRANDI, Emma. "Mulheres agricultoras no Brasil: sujetos políticos na luta por soberanía e seguranca alimentar". Pensamiento iberoamericano, v.9, p.169-183, 2011.

SILIPRANDI, Emma. Mulheres e agroecologia: transformando as florestas, o campo e as pessoas. Rio de Janeiro: Editora UFRJ, 2015.

TRONTO, Joan. "Beyond gender difference to a theory of care". Signs: Journal of Women in Culture and Society, v. 12, n.4, p.644-663, 1987.

VASCONCELLOS, Bruna M. "Mulheres rurais, trabalho associado e agroecologia". In: NOVAES, Henrique N.; MAZIN, Diogo; SANTOS, Lais (Orgs.). Questão Agrária, Cooperação e Agroecologia. Vol. 1. 1ª ed. São Paulo: Outras Expressões, 2015.

VASCONCELLOS, Bruna M. Politizando o cuidar: as mulheres do Sul na construção de alternativas sociotécnicas. 2017. Tese de Doutorado em Política Científica e Tecnológica. Universidade Estadual de Campinas, Campinas, São Paulo, Brasil.

Recebido em 30/06/2020.

Aceito em 20/11/2020. 